EARTH STRAIN

\section{A Growth Industry?}

from a Correspondent

THERE have been many measurements of strain near the surface of the Earth (particularly strains and tilts caused by tides in the Earth), but the contribution of this work to the detailed knowledge of the Earth and earthquake sources has been small. This situation should now change as the number of strainmeter installations multiply and work begins on the interpretation of the results. At least these were the two main impressions given by the contributors to the discussion meeting on the measurement and interpretation of strain at the Royal Society on May 11 and 12.

The principal reasons for the renewed interest in strain seem to be: first, many new instruments are available for strain measurement, particularly cheap and portable strainmeters; second, strain measurement may provide the key to earthquake prediction (another growth point in the Earth sciences); and, third, abrupt change in strain and tilt (strain and tilt steps) associated with earthquakes can apparently be recorded at long range.

Dr G. C. P. King (University of Cambridge) described the development of strainmeters from the primitive attempts of Milne in 1888 using a $1 \mathrm{~m}$ steel bar as a length standard to the modern interferometer strainmeters which use laser beams tens of metres long as a standard. These laser strainmeters, however, have the disadvantage that they are expensive and not readily portable though they are highly sen- sitive. Dr J. Levine (University of Colorado) described an experiment using such an ultra-sensitive strainmeter to search for gravity waves and showed that if any such waves exist they must produce strains of less than $3 \times 10^{-17}$.

Dr King suggested that the most important advance in recent years was the development of cheap portable wire strainmeters which give satisfactory results if simply installed in a shallow trench in sand or clay. Rigid attachment of the strainmeter to solid rock (usually in a tunnel or vault) is not required. Several such meters could thus be installed around any chosen site and the outputs of all the instruments combined. This procedure should reduce local site effects which can be large, as was demonstrated by Dr W. H. Ward (Building Research Station) who described the large, local ground strains that can be induced by civil engineering projects.

Mr R. V. Allen (National Center for Earthquake Research, California) also described a portable strain measuring instrument-a tiltmeter, suitable for installing in boreholes, which uses a simple pendulum with a capacitance transducer and has about the same sensitivity $\left(10^{-8}\right.$ radian) as larger and more cumbersome liquid level tiltmeters. Again, rather surprisingly, this instrument gives reliable results when simply installed in a sand dune.

Many strain and tiltmeters of a wide variety of designs are already in operation in California as part of a large scale programme aimed eventually at earthquake prediction. Dr R. G. Nason (Earthquake Mechanism Laboratory, San Francisco) listed five universities

\section{Swing Wing or Swivel for SST ?}

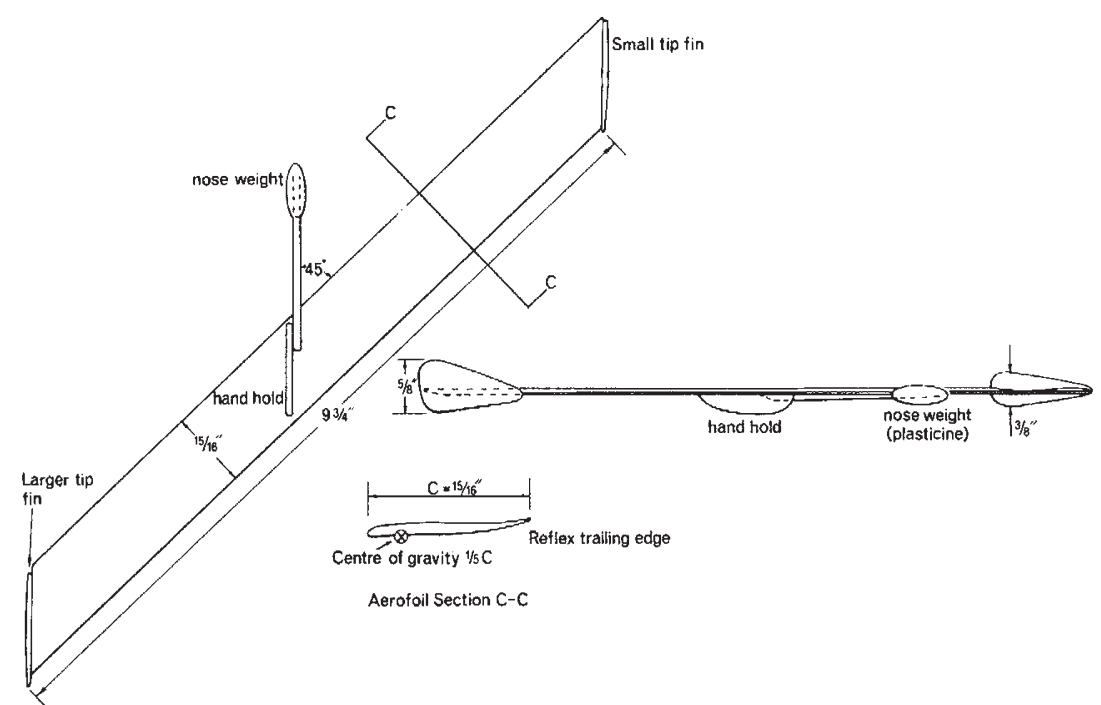

THIS is R. T. Jones's plan of a model to test the feasibility of a new concept for a supersonic aircraft, which was described last week in Nature (237, 252; 1972). The asymmetrical orientation of the wing in the model, which should be made from 1/16 inch balsa wood, is that envisaged for supersonic flight. At take off an aircraft built in this way would have its wing perpendicular to the fuselage. and three government agencies currently working in the California area and one gained the impression that the San Andreas fault was slowly being stitched together by instruments spanning the fault. Dr Nason showed that sensitive instruments are not required to demonstrate fault movement in this part of California; man-made objects such as pavements and concrete lined ditches show effects indicating creep rates of the order of $10 \mathrm{~mm} /$ year.

One of the interesting features shown by this instrumentation, however, is the occurrence of "creep events"-periods of relatively rapid creep along the faults. Dr C.-Y. King (Earthquake Mechanism Laboratory, San Francisco) described these criep events as similar to seismic faulting with failure propagating along the fault but with very low velocity (10 $\mathrm{km} /$ day or less at the surface) and maximum slip velocities of 0.1 to 10 $\mu \mathrm{m} \mathrm{s} \mathrm{s}^{-1}$. These velocities are much lower than those in seismic faulting and so they do not excite seismic waves. Similar, slowly propagating tilts were described by Professor K. Kasahara (University of Tokyo), who reviewed current earthquake fault studies in Japan with particular reference to work in the vicinity of the epicentre of the Great Kanto earthquake of 1923. Current measurements of strain accumulation in this area are consistent with the fault model proposed from seismological studies.

The most controversial observations described at the meeting were the tilt and strain steps associated with earthquakes and recorded at long range (up to $9,000 \mathrm{~km}$ ). Nobody seemed to doubt that strain steps occur. Dr J. Berger (University of California, La Jolla), for example, recorded such a step from the recent destructive San Fernando (California) earthquake, but the recording station was only $200 \mathrm{~km}$ from the epicentre; no such steps had been recorded at this station from earthquakes at much greater distances. Dr E. Berg (University of Alaska), however, reported tilt steps recorded in Alaska from earthquakes in New Guinea, Chile and the Solomon Islands. These tilt steps seem to propagate with velocities of around $3.0 \mathrm{~km} \mathrm{~s}^{-1}$ and less and cannot, according to Dr Berg, be explained on purely elastic theory. They may instead propagate as plastic waves.

In discussion Professor F. Press (Massachusetts Institute of Technology) said that if these tilt steps are real (and not artefacts) they implied that the area of movement on the fault plane during an earthquake is much larger than the studies of conventional seismic signals indicate. At the current rate at which strain and tiltmeters are being installed it should not be long before this question of strain and tilt steps recorded at long range is resolved. 